\title{
Efficacy and safety of indacaterol/glycopyrronium in Japanese patients with COPD: a subgroup analysis from the SHINE study
}

This article was published in the following Dove Press journal:

International Journal of COPD

II October 2016

Number of times this article has been viewed

\section{Shu Hashimoto' \\ Hisataro Ikeuchi² \\ Shujiro Murata ${ }^{2}$ \\ Tetsuji Kitawaki ${ }^{2}$ \\ Kimitoshi Ikeda ${ }^{2}$ \\ Donald Banerji ${ }^{3}$}

'Division of Respiratory Medicine, Department of Internal Medicine, Nihon University School of Medicine, Tokyo, Japan; ${ }^{2}$ Novartis Pharma KK, Minato-ku, Tokyo, Japan; ${ }^{3}$ Novartis Pharmaceuticals Corporation, East Hanover, NJ, USA
Correspondence: Shu Hashimoto Division of Respiratory Medicine, Department of Internal Medicine, Nihon University School of Medicine, 30-I, Ohyaguchikamimachi, Itabashi-ku, Tokyo 173-86I0, Japan

Tel +8I 339727552

Email hashimoto.shu@nihon-u.ac.jp
Background: COPD-related deaths are increasing in Japan, with $\sim 5.3$ million people at risk. Methods: The SHINE was a 26-week, multicenter, randomized, double-blind, parallel-group study that evaluated safety and efficacy of indacaterol (IND)/glycopyrronium (GLY) 110/50 $\mu \mathrm{g}$ once daily (od) compared with GLY $50 \mu \mathrm{g}$ od, IND $150 \mu \mathrm{g}$ od, open-label tiotropium (TIO) $18 \mu \mathrm{g}$ od, and placebo. The primary end point was trough forced expiratory volume in 1 second $\left(\mathrm{FEV}_{1}\right)$ at Week 26. Other key end points included peak $\mathrm{FEV}_{1}$, area under the curve for FEV from 5 minutes to 4 hours $\left(\mathrm{FEV}_{1} \mathrm{AUC}_{5 \mathrm{~min}-4 \mathrm{~h}}\right)$, Transition Dyspnea Index focal score, St George's Respiratory Questionnaire total score, and safety. Here, we present efficacy and safety of IND/GLY in the Japanese subgroup.

Results: Of 2,144 patients from the SHINE study, 182 (8.5\%) were Japanese and randomized to IND/GLY ( $n=42)$, IND $(n=41)$, GLY $(n=40)$, TIO $(n=40)$, or placebo $(n=19)$. Improvement in trough $\mathrm{FEV}_{1}$ from baseline was $190 \mathrm{~mL}$ with IND/GLY and treatment differences versus IND $(90 \mathrm{~mL}), \mathrm{GLY}(100 \mathrm{~mL}), \mathrm{TIO}(90 \mathrm{~mL})$, and placebo $(280 \mathrm{~mL})$ along with a rapid onset of action at Week 26. IND/GLY showed an improvement in $\mathrm{FEV}_{1} \mathrm{AUC}_{5 \min -4 \mathrm{~h}}$ versus all comparators (all $P<0.05)$. All the treatments were well tolerated and showed comparable effect on Transition Dyspnea Index focal score and St George's Respiratory Questionnaire total score. The effect of IND/GLY in the Japanese subgroup was consistent to overall SHINE study population.

Conclusion: IND/GLY demonstrated superior efficacy and comparable safety compared with its monocomponents, open-label TIO, and placebo and may be used as a treatment option for the management of moderate-to-severe COPD in Japanese patients.

Keywords: SHINE study, Japanese subgroup, COPD, indacaterol/glycopyrronium, open-label tiotropium

\section{Introduction}

COPD was the tenth most common cause of disease-related deaths in Japan in 2014, and it was found that the number of COPD-related deaths is increasing. ${ }^{1}$ An epidemiological survey in Japanese population revealed that the prevalence of physiciandiagnosed COPD in Japan is increasing, and $\sim 8.6 \%$ of the patients aged $\geq 40$ years are suffering from COPD. An estimated population of 5.3 million Japanese are now at risk of developing COPD; however, only a small proportion (9.4\%) were diagnosed to have COPD. ${ }^{2,3}$

Decline in quality of life due to breathlessness is the major challenge in the management of COPD that demands sustained improvement in lung function. ${ }^{4}$ Longacting bronchodilators of different pharmacological classes, either as monotherapy or in combination, are now the preferred choice and proven cornerstone for treating 
compromised airflow in patients with COPD. ${ }^{4}$ In situations where a single bronchodilator fails to provide the desired effect, both Global Initiative for Chronic Obstructive Lung Disease (GOLD) strategy and Japanese Respiratory Society (JRS) guidelines recommend the use of a fixed-dose combination of a long-acting $\beta_{2}$-agonist (LABA) and a longacting muscarinic antagonist (LAMA) for management of symptomatic patients with COPD. ${ }^{4,5}$ A fixed-dose LABA/ LAMA combination, indacaterol (IND)/glycopyrronium (GLY), was evaluated in 14 controlled trials as maintenance treatment for patients with COPD. Outcomes of these studies demonstrated better efficacy of IND/GLY in terms of improving lung function and quality of life, with a comparable safety profile versus placebo, ${ }^{6-8}$ LAMA, open-label tiotropium (TIO), ${ }^{9}$ and a combination of LABA/inhaled corticosteroid (ICS) and salmeterol/fluticasone $(50 / 500 \mu \mathrm{g})$ in patients with moderate-to-severe COPD. Most of these trials have been conducted in Caucasian patients; however, two studies, SHINE and ARISE, evaluated the efficacy of IND/GLY in a Japanese patient subgroup as well. ${ }^{10,11}$ In the overall population of the SHINE study, IND/GLY showed superior improvements in lung function and health status compared with placebo, IND, GLY, and open-label TIO with a similar safety profile in patients with COPD.${ }^{10}$ Here, we report the efficacy and safety of IND/GLY in the Japanese subgroup of patients from the SHINE study.

\section{Methods}

SHINE was a 26-week, multicenter, randomized, doubleblind, parallel-group, placebo- and active-controlled study (www.ClinicalTrial.gov identifier NCT01202188). ${ }^{10}$ After the eligibility assessments, patients were randomized (2:2:2:2:1) to receive once daily (od) IND/GLY 110/50 $\mu \mathrm{g}$, IND $150 \mu \mathrm{g}$, GLY $50 \mu \mathrm{g}$, open-label TIO $18 \mu \mathrm{g}$, or matching placebo. IND/GLY, IND, GLY, and placebo were administered via the Breezhaler ${ }^{\circledR}$ device, whereas TIO was delivered via the HandiHaler ${ }^{\circledR}$ device. Men and women aged $\geq 40$ years with moderate-to-severe stable COPD and a smoking history of $\geq 10$ pack-years who had a postbronchodilator forced expiratory volume in 1 second $\left(\mathrm{FEV}_{1}\right) \geq 30 \%$ and $<80 \%$ of predicted normal value and a postbronchodilator $\mathrm{FEV}_{1} /$ forced vital capacity ratio $<0.70$ were included in the study. The key exclusion criterion was COPD exacerbation that required treatment with antibiotics, systemic steroids (oral or intravenous), or hospitalization during 6 weeks prior to screening or before randomization. During the study, salbutamol/albuterol was permitted as a rescue medication. Informed consent was taken from all the eligible patients. The study was performed in accordance with the Declaration of Helsinki, Good Clinical Practice guidelines, and all applicable regulatory requirements and was approved by the Ministry of Health, Labor and Welfare, Japan, as well as all relevant national and local ethics review boards (Table S1).

\section{Assessments}

The primary end point of the study was trough $\mathrm{FEV}_{1}$ (mean of $\mathrm{FEV}_{1}$ values measured at 23 hours 15 minutes and 23 hours 45 minutes) after IND/GLY administration at Week 26 versus IND and GLY. Other key end points included peak FEV ${ }_{1}$, area under the curve for $\mathrm{FEV}_{1}$ from 5 minutes to 4 hours $\left(\mathrm{FEV}_{1} \mathrm{AUC}_{5 \min -4 \mathrm{~h}}\right)$, and trough $\mathrm{FEV}_{1}$ throughout the study period. Nonspirometric analysis included the Transition Dyspnea Index (TDI) focal score and St George's Respiratory Questionnaire (SGRQ) total score at Week 26. Safety was assessed by monitoring adverse events (AEs) and serious AEs over the 26-week study period.

\section{Statistical analysis}

Data were analyzed using a linear mixed model, which included $\mathrm{FEV}_{1}$ as the dependent variable, treatment as an fixed effect, the variables $\left(\mathrm{FEV}_{1}\right.$, ICS use, $\mathrm{FEV}_{1}$ reversibility components, and smoking status) at baseline as covariates, and centre as a random effect. The estimated treatment differences were presented as least-squares mean with standard errors and the associated $95 \%$ confidence interval. The secondary efficacy variables, which included peak $\mathrm{FEV}_{1}, \mathrm{FEV}_{1} \mathrm{AUC}_{5 \min -4 \mathrm{~h}}$, trough $\mathrm{FEV}_{1}$ over 26 weeks, TDI focal score, and SGRQ total score, were also analyzed using the same mixed model as specified for the analysis of the primary variable, with the appropriate baseline measurement included as a covariate. ${ }^{10}$ In addition, the proportions of patients who achieved a clinically important improvement in the SGRQ and TDI focal score were analyzed using logistic regression as specified for the analysis of the primary variable, with the appropriate baseline measurement included as a covariate.

\section{Results}

\section{Patient characteristics}

Of the total 2,144 patients randomized in the SHINE study, $182(8.5 \%)$ were Japanese and randomized to receive IND/ GLY 110/50 $\mu \mathrm{g}(\mathrm{n}=42)$, IND $110 \mu \mathrm{g}(\mathrm{n}=41)$, GLY $50 \mu \mathrm{g}$ $(\mathrm{n}=40)$, open-label TIO $18 \mu \mathrm{g}(\mathrm{n}=40)$, and matching placebo $(n=19)$. The baseline demographic and clinical characteristics of the patients were comparable across all the groups (Table 1). More than $90 \%$ of the patients in the Japanese cohort were men aged $>68$ years, and their mean percentage 
Table I Demographic and baseline clinical characteristics of the Japanese subgroup

\begin{tabular}{|c|c|c|c|c|c|}
\hline & IND/GLY (n=42) & IND $(n=4 I)$ & GLY $(n=40)$ & TIO* $(n=40)$ & Placebo $(n=19)$ \\
\hline Age, years & $71.0(6.92)$ & $69.2(5.96)$ & $69.0(8.87)$ & $67.8(9.25)$ & $68.9(5.22)$ \\
\hline Sex, male, n (\%) & $42(100)$ & 40 (97.6) & $38(95.0)$ & $37(92.5)$ & 18 (94.7) \\
\hline Body mass index, $\mathrm{kg} / \mathrm{m}^{2}$ & $22.4(3.35)$ & $22.7(3.17)$ & $22.2(3.05)$ & $22.8(3.54)$ & $24.3(1.86)$ \\
\hline Smoking history, pack-years & $64.7(25.21)$ & $59.9(27.7 I)$ & $69.8(33.36)$ & $64.7(38.25)$ & $52.3(20.20)$ \\
\hline \multicolumn{6}{|l|}{ Smoking status, n (\%) } \\
\hline Ex-smoker & 31 (73.8) & 31 (75.6) & $31(77.5)$ & $29(72.5)$ & 17 (89.5) \\
\hline Current smoker & II (26.2) & $10(24.4)$ & $9(22.5)$ & II (27.5) & $2(10.5)$ \\
\hline \multicolumn{6}{|l|}{ ICS use at baseline, $\mathrm{n}(\%)$} \\
\hline No & 31 (73.8) & $30(73.2)$ & $28(70.0)$ & $29(72.5)$ & I4 (73.7) \\
\hline Yes & II (26.2) & II (26.8) & $12(30.0)$ & II (27.5) & $5(26.3)$ \\
\hline \multicolumn{6}{|l|}{$\begin{array}{l}\text { Number of COPD exacerbations in the previous } \\
\text { year, } n(\%)\end{array}$} \\
\hline 0 & $39(92.9)$ & $32(78.0)$ & $31(77.5)$ & $33(82.5)$ & $17(89.5)$ \\
\hline 1 & $2(4.8)$ & $9(22.0)$ & $8(20.0)$ & $7(17.5)$ & I (5.3) \\
\hline$\geq 2$ & I (2.4) & 0 & I (2.5) & 0 & $\mathrm{I}(5.3)$ \\
\hline \multicolumn{6}{|l|}{ Severity of COPD (GOLD 2008), n (\%) } \\
\hline Moderate COPD & $32(76.2)$ & $31(75.6)$ & $35(87.5)$ & $28(70.0)$ & 14 (73.7) \\
\hline Severe COPD & $10(23.8)$ & $10(24.4)$ & $4(10.0)$ & $12(30.0)$ & $5(26.3)$ \\
\hline Duration of COPD, years & $3.6(3.23)$ & $3.9(5.01)$ & $4.0(3.80)$ & $3.4(2.10)$ & $3.2(2.78)$ \\
\hline $\mathrm{FEV}_{\text {, }}$, prebronchodilator, $\mathrm{L}$ & $1.36(0.44)$ & $1.32(0.43)$ & $\mathrm{I} .35(0.4 \mathrm{I})$ & $1.22(0.42)$ & $1.27(0.38)$ \\
\hline $\mathrm{FEV}_{\text {, }}$, postbronchodilator, $\mathrm{L}$ & $1.60(0.42)$ & $1.54(0.46)$ & $1.56(0.42)$ & $1.48(0.45)$ & $1.47(0.46)$ \\
\hline FEV $(\mathrm{L})$ postbronchodilator (\% predicted FEV ) & $61.357(|3.094|)$ & $60.268(14.8594)$ & $61.300(11.4672)$ & $57.600(12.8797)$ & $57.474(13.1376)$ \\
\hline $\begin{array}{l}\mathrm{FEV} \text {, reversibility after inhalation of } \\
\text { bronchodilator }(\%)\end{array}$ & $20.167(\mid 3.3543)$ & I8.829 (I3.6874) & $17.000(|2.748|)$ & $23.800(15.4026)$ & $15.737(9.433 \mid)$ \\
\hline
\end{tabular}

Note: Data are represented as mean (standard deviation) unless otherwise specified. *Open label.

Abbreviations: IND, indacaterol; GLY, glycopyrronium; TIO, tiotropium; ICS, inhaled corticosteroid; FEV , forced expiratory volume in I second; GOLD, Global Initiative for Chronic Obstructive Lung Disease.

of predicted postbronchodilator $\mathrm{FEV}_{1}$ was $\sim 60 \%$, with only $19 \%$ reversibility of $\mathrm{FEV}_{1}$ after bronchodilation. More than $75 \%$ of patients had moderate-to-severe COPD according to the GOLD 2009 guidelines, and almost $10 \%$ of patients in the Japanese subgroup were having a history of COPD exacerbation in the previous year and $\sim 25 \%$ were using ICS at baseline. In total, 160 patients $(87.9 \%)$ completed the study; the major reasons for discontinuation from the study were AEs and withdrawal of consent by the patients (Figure 1).

\section{Lung function}

The primary efficacy end point of the SHINE study was achieving a $190 \mathrm{~mL}$ improvement in trough $\mathrm{FEV}_{1}$ from baseline with IND/GLY in Japanese patients. Improvement in lung function was greater in Japanese patients treated using IND/GLY compared with IND (90 mL), GLY (100 mL), TIO (90 mL), and placebo (280 mL; Figure 2). ${ }^{10}$ The spirometric profile in terms of trough $\mathrm{FEV}_{1}$ with IND/GLY was superior compared with TIO and placebo on Day 2 and Week 26, with treatment differences ranging from $90 \mathrm{~mL}$ to $290 \mathrm{~mL}$ (Figure 3). IND/GLY showed greater improvements in peak $\mathrm{FEV}_{1}$ from 5 minutes to 4 hours compared with IND, GLY, TIO, and placebo at Week 26, with treatment differences ranging from $100 \mathrm{~mL}$ to $390 \mathrm{~mL}$ (all $P<0.01$; Figure 4). In addition, an improvement in lung function was also observed with IND/GLY in terms of $\mathrm{FEV}_{1} \mathrm{AUC}_{5 \mathrm{~min}-4 \mathrm{~h}}$ compared with IND, GLY, TIO, and placebo, at the end of study, with treatment differences ranging from $90 \mathrm{~mL}$ to $380 \mathrm{~mL}$ (all $P<0.05$; Figure 5).

\section{Patient-reported outcomes}

Dyspnea control in terms of improvement in TDI focal score in the Japanese subgroup was comparable across all treatment groups. Treatment differences between IND/GLY versus placebo were 0.67 units and versus IND, GLY, TIO were 0.69 units, 0.03 units, and 0.65 units, respectively. A higher proportion of patients achieved a clinically meaningful improvement in the TDI focal score ( $\geq 1$ unit) with IND/ GLY versus IND (odds ratio [OR], 1.60), GLY (OR, 1.01), TIO (OR, 1.16), and placebo (OR, 1.15).

Improvement in health status assessed via reduction in the SGRQ total score was similar across all treatment groups in the Japanese patient subgroup. Treatment differences in the SGRQ total score between IND/GLY vs placebo, IND, GLY, and TIO were -1.31 units, -0.48 units, -3.75 units, and -0.96 units, respectively. The proportion of patients 


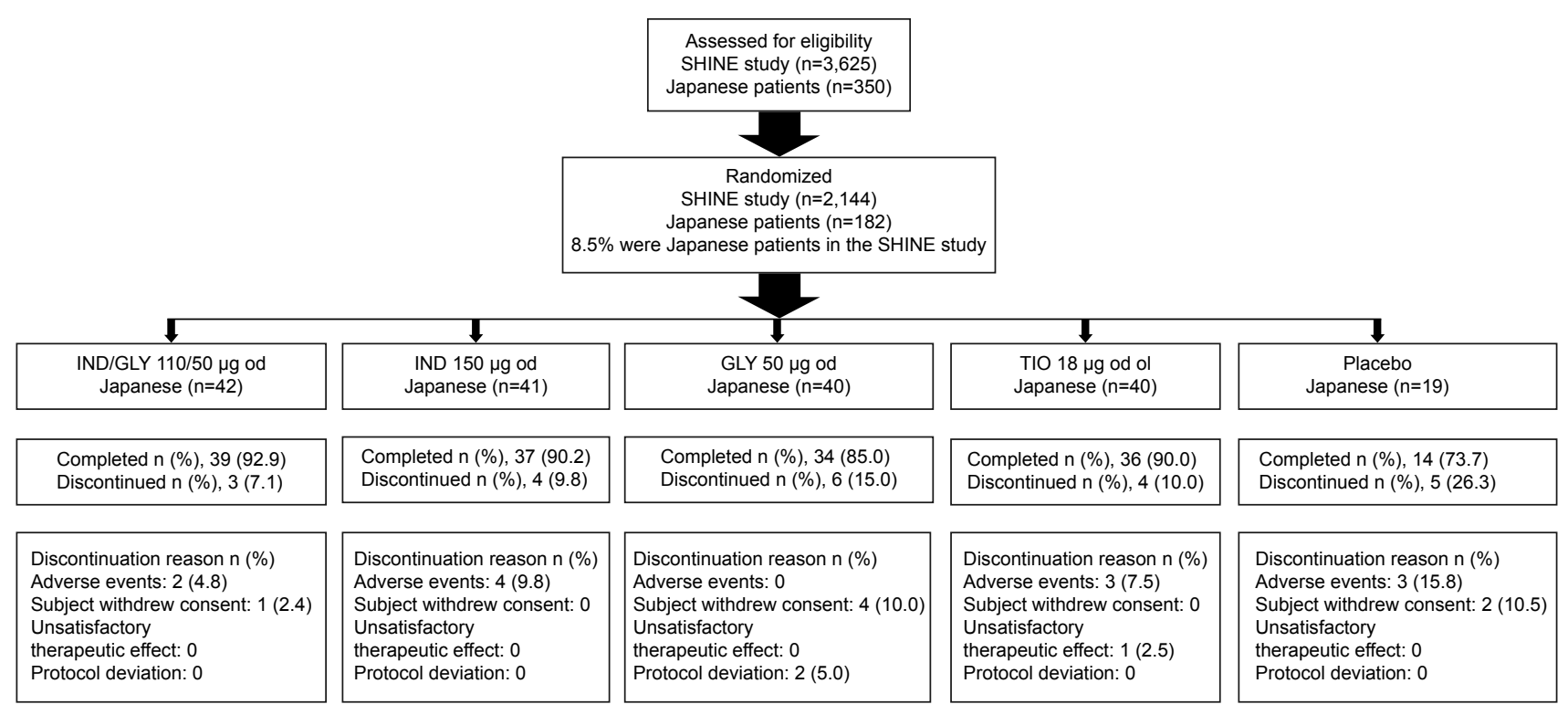

Figure I Patient disposition.

Note: $n$, number of patients.

Abbreviations: IND, indacaterol; GLY, glycopyrronium; od, once daily; TIO, tiotropium; ol, open label.

achieving a clinically meaningful improvement in the SGRQ total score ( $\geq 4$-unit reduction) was highest with IND/GLY compared to IND (OR, 1.69), GLY (OR, 3.13), TIO (OR, 2.36), and placebo (OR, 0.86).

\section{Safety}

The overall incidence of AEs was similar across the five treatment groups, and the lowest incidence was reported for patients treated with IND/GLY (21 (50\%); IND, 27 (65.9\%); GLY, 24 (60.0\%); TIO, 31 (77.5\%); and placebo, 12 (63.2\%); Table 2). COPD exacerbations were found to be the frequent AEs in

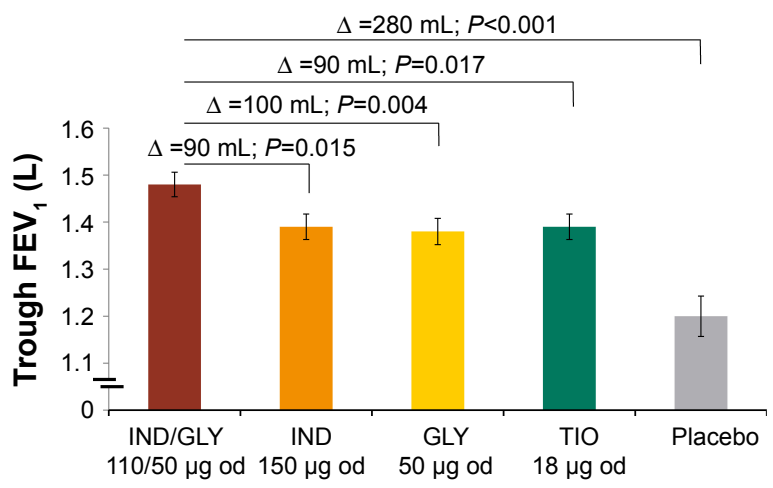

Figure 2 Trough FEV $(\mathrm{L})$ after 26 weeks in the Japanese subgroup. Notes: Data are presented as LSM (standard error). Trough FEV is defined as the average of the post dose 23 hours 15 minutes and 23 hours 45 minutes FEV, values (excluding values taken outside 22 hours 45 minutes and 24 hours 15 minutes post dose) at Day 2.

Abbreviations: $\mathrm{FEV}_{1}$, forced expiratory volume in I second; LSM, least-squares mean; IND, indacaterol; GLY, glycopyrronium; od, once daily; TIO, tiotropium; $\Delta$, treatment difference. all treatment groups, with their lowest occurrence in patients treated with IND/GLY ( $12 \%)$. Serious AEs were comparable across all treatment groups. Moreover, no cardiovascular AEs, major adverse cardiac events, cerebro-cardiovascular AEs, abnormal changes from baseline QTc in resting ECG was obtained using Bazett's formula (QTcB), Fridericia's formula $(\mathrm{QTcF})(<10$ mlliseconds) or heart rate, or imbalance in hematocrit values was observed in the Japanese subgroup.

\section{Discussion}

The aim of this post hoc analysis was to explore the efficacy and safety profile of IND/GLY in the Japanese subgroup of the SHINE study. Based on the overall results of the SHINE study, the efficacy of IND/GLY was superior to that of placebo, with comparable safety. ${ }^{10}$ The results of this analysis support our claim that IND/GLY improves lung function and health status in patients with moderate-to-severe COPD with compromised airflow according to the GOLD guidelines, irrespective of ethnicity. The fourth edition of the JRS guidelines, which is customized for the Japanese scenario, recommend LAMA/LABA for the management of moderate-to-severe COPD with symptoms and the use of ICS in combination with LABA or LAMA only if the condition does not improve. ${ }^{4,5,12}$ GOLD strategy that considers diverse ethnicity as well as various COPD phenotypes differs from the JRS guidelines, which are specific for the Japanese population, in terms of prescribing ICS., ${ }^{4,5}$ The difference in 


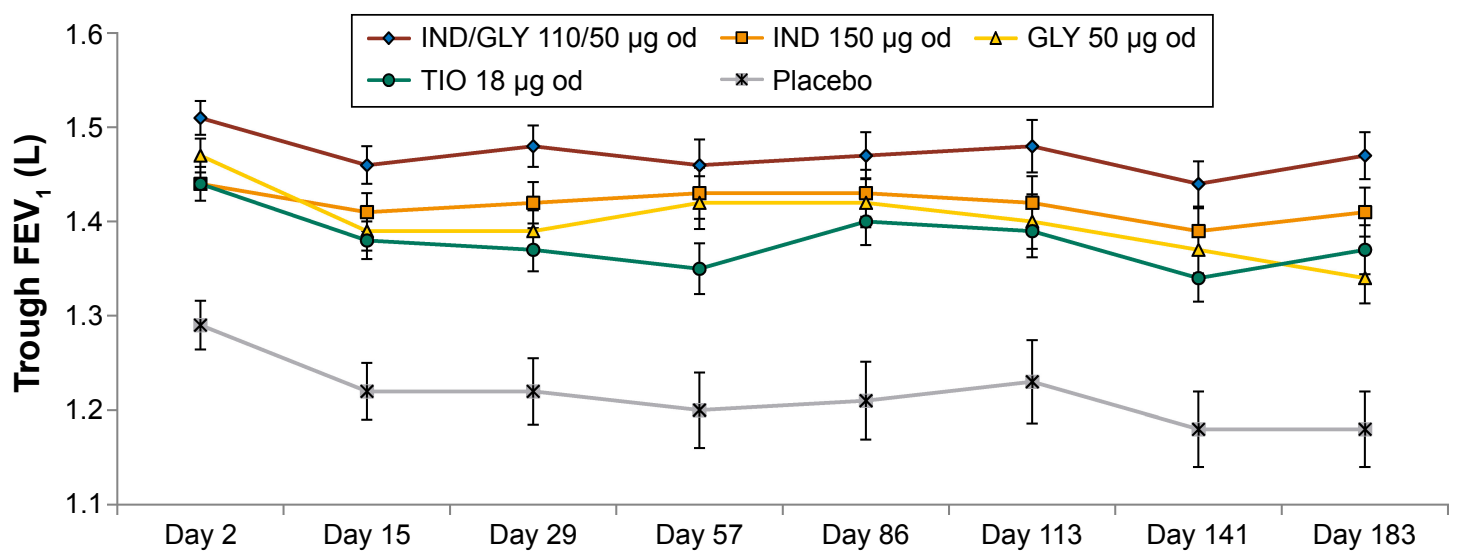

Figure 3 Trough FEV, (L) over 26 weeks in the Japanese subgroup.

Note: Data are presented as LSM (standard error).

Abbreviations: $\mathrm{FEV}_{1}$, forced expiratory volume in I second; LSM, least-squares mean; IND, indacaterol; GLY, glycopyrronium; od, once daily; TIO, tiotropium.

the recommendations may be due to the fact that Japanese patients with COPD experience fewer COPD exacerbations compared to Caucasians. ${ }^{12}$ In the Japanese subgroup of the SHINE study, we observed greater improvements in lung function with IND/GLY versus IND, GLY, and TIO monotherapies, although the improvement in quality of life was comparable across all groups. The results of this subgroup analysis were similar to those observed in the entire study population. ${ }^{10}$ The small sample size is perhaps responsible for the lower baseline $\mathrm{FEV}_{1}$ observed in the TIO group $(1.22 \mathrm{~L})$ than the IND/GLY group $(1.36 \mathrm{~L})$, which was at least partially responsible for the $90 \mathrm{~mL}$ "treatment effect" of IND/GLY versus TIO at the end of 26 weeks. However, baseline $\mathrm{FEV}_{1}$ was used as a covariate in the statistical analysis, and the treatment effect was adjusted to account for the

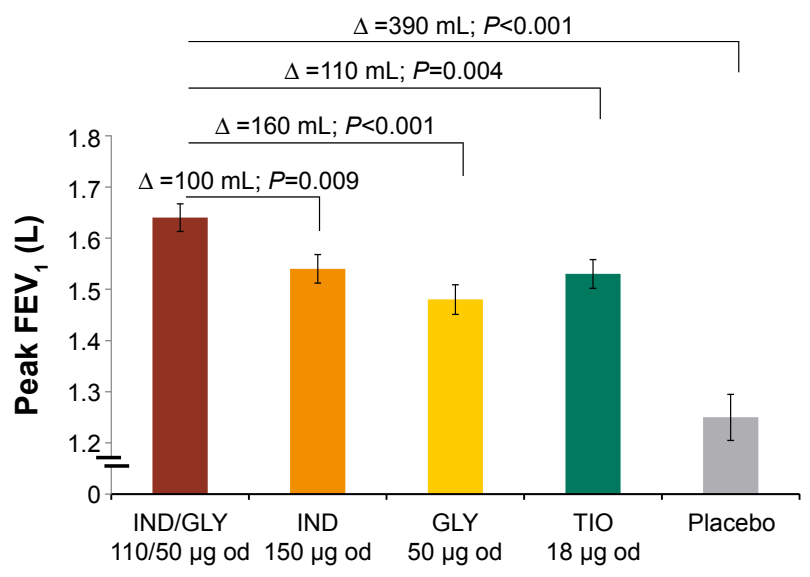

Figure 4 Peak FEV , (L) from 5 minutes to 4 hours at Week 26 in the Japanese subgroup.

Notes: Data are presented as LSM (standard error). Peak FEV is defined as the maximum FEV during the first 4 hours after dosing.

Abbreviations: $\mathrm{FEV}_{1}$, forced expiratory volume in I second; LSM, least-squares mean; IND, indacaterol; GLY, glycopyrronium; od, once daily; TIO, tiotropium; $\Delta$, treatment difference. baseline difference in $\mathrm{FEV}_{1}$ between the IND/GLY and TIO groups. The aforementioned findings were similar to those reported in another study, wherein baseline $\mathrm{FEV}_{1}$ affected the treatment efficacy of a bronchodilator, which showed a smaller change from baseline $\mathrm{FEV}_{1}$ value in patients with lower baseline $\mathrm{FEV}_{1} \cdot{ }^{13}$ In addition to the observed improvements in trough $\mathrm{FEV}_{1}$, our study also demonstrated rapid bronchodilation with IND/GLY in terms of $\mathrm{FEV}_{1} \mathrm{AUC}_{5 \min -4 \mathrm{~h}}$ compared to the monotherapy components, TIO, and placebo. In previous studies, spirometric outcomes of IND/ GLY treatment showed a comparable reduction in the rate of COPD exacerbations, along with superior improvement in lung function versus its monotherapy components, TIO, and salmeterol/fluticasone and without considerable variations in the TDI focal score and SGRQ total score among different treatment groups. ${ }^{9,11,14,15}$ In our study, the results of the Japanese subgroup analysis showed comparable improvements in the TDI focal score and SGRQ total score, which

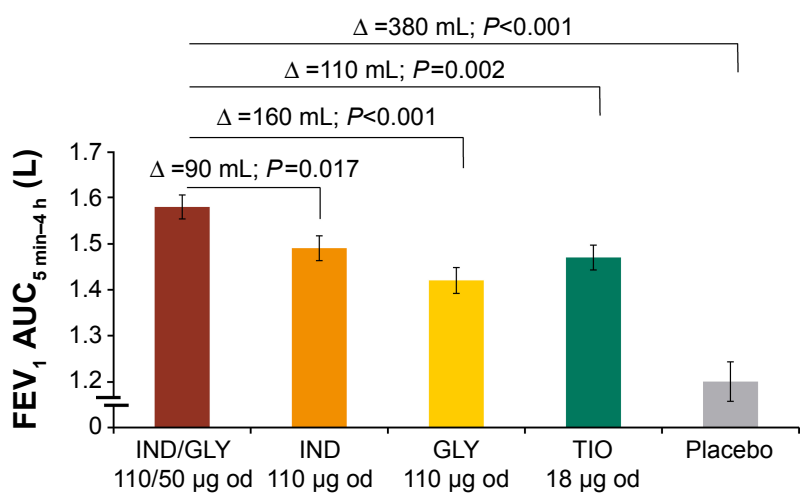

Figure $5 \mathrm{FEV}_{1} \mathrm{AUC}_{5 \min -4 \mathrm{~h}}(\mathrm{~L})$ at Week 26 in the Japanese subgroup.

Note: Data are presented as LSM (standard error).

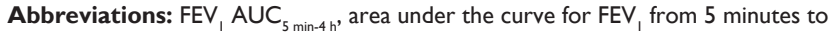
4 hours; $\mathrm{FEV}_{1}$, forced expiratory volume in I second; LSM, least-squares mean; IND, indacaterol; GLY, glycopyrronium; od, once daily; TIO, tiotropium; $\Delta$, treatment difference. 
Table 2 Summary of AEs and SAEs by preferred terms in the Japanese subgroup

\begin{tabular}{|c|c|c|c|c|c|}
\hline & IND/GLY (n=42) & IND $(n=4$ I) & GLY $(n=40)$ & TIO $(n=40)$ & Placebo $(n=19)$ \\
\hline Total AEs & $21(50.0)$ & 27 (65.9) & $24(60.0)$ & $31(77.5)$ & $12(63.2)$ \\
\hline \multicolumn{6}{|l|}{$A E s \geq 2$ incidences in any group } \\
\hline $\mathrm{COPD}^{\mathrm{a}}$ & $5(11.9)$ & $7(17.1)$ & $6(15.0)$ & $10(25.0)$ & $6(31.6)$ \\
\hline Nasopharyngitis & $4(9.5)$ & $10(24.4)$ & $9(22.5)$ & $9(22.5)$ & $5(26.3)$ \\
\hline Cough & $2(4.8)$ & $2(4.9)$ & 0 & 0 & 0 \\
\hline Productive cough & $2(4.8)$ & 0 & 0 & 0 & 0 \\
\hline Constipation & $2(4.8)$ & $2(4.9)$ & $3(7.5)$ & 0 & 0 \\
\hline Bronchitis & I (2.4) & 0 & 0 & $3(7.5)$ & I (5.3) \\
\hline Upper respiratory tract infection & I (2.4) & I (2.4) & 0 & $2(5.0)$ & I (5.3) \\
\hline GERD & 0 & $2(4.9)$ & I (2.5) & 0 & 0 \\
\hline Back pain & 0 & 0 & $3(7.5)$ & 0 & 0 \\
\hline Drug-related AEs & $7(16.7)$ & $5(12.2)$ & $4(10.0)$ & $5(12.5)$ & 0 \\
\hline \multicolumn{6}{|c|}{ AEs leading to permanent discontinuation of study drugs } \\
\hline Total SAEs & I (2.4) & $5(12.2)$ & $2(5.0)$ & I (2.5) & $2(10.5)$ \\
\hline
\end{tabular}

Notes: Data are presented as number of patients (percentage). alncludes COPD exacerbation or COPD worsening.

Abbreviations: AEs, adverse events; SAEs, serious adverse events; IND, indacaterol; GLY, glycopyrronium; TIO, tiotropium; GERD, gastroesophageal reflux disease.

is consistent with the results of a previous study. ${ }^{14} \mathrm{~A}$ higher proportion of patients from the IND/GLY group achieved minimal clinically important differences for TDI and SGRQ compared with the other treatment groups. Moreover, the number of patients in the Japanese subgroup was small to determine the significant improvement in the TDI focal score and SGRQ total score.

The SHINE study demonstrated that safety profile of IND/ GLY in Japanese patients with COPD was consistent with the overall study population. ${ }^{10}$ The most frequently reported AE was COPD exacerbation in the Japanese subgroup, and the occurrence was $\sim 12 \%$, which was lower compared with TIO $(25 \%)$ and placebo $(-32 \%)$. Furthermore, the incidents of exacerbations were lesser in the Japanese subgroup than the overall study population, where $\sim 39 \%$ exacerbations were reported. This fact was supported by the results of a previous study that demonstrated that IND/GLY was superior in preventing moderate-to-severe COPD exacerbations compared with TIO, with concomitant improvements in lung function and health status. ${ }^{9}$ A pooled analysis of 14 randomized clinical trials with data from 11,404 patients with COPD demonstrated that IND/GLY did not increase the risk of investigated safety end points and had a comparable safety profile as its monocomponents, TIO, and placebo. ${ }^{16}$

\section{Conclusion}

Based on the results of this subgroup analysis, we can conclude that the efficacy and safety of IND/GLY in the Japanese population were similar to that in the overall study population of the SHINE study; thus, IND/GLY may be considered as a treatment option for the management of Japanese patients with moderate-to-severe COPD.

\section{Acknowledgments}

The authors would like to thank their colleagues who were involved in the planning, execution, and analysis of the SHINE study and all the study participants. This study was sponsored by Novartis Pharma AG, Basel, Switzerland. The authors were assisted in the preparation of this manuscript by Kevin Roche and Santanu Bhadra of Novartis Healthcare Pvt. Ltd., Hyderabad, India.

\section{Author contributions}

All authors contributed toward data analysis, drafting and critically revising the paper and agree to be accountable for all aspects of the work.

\section{Disclosure}

SH had received grants and/or lecture fees from Astellas Pharma Inc., AstraZeneca K.K., Chugai Pharmaceutical Co. Ltd., GlaxoSmithKline K.K., KYORIN Pharmaceutical Co., Ltd., Nippon Boehringer Ingelheim Co. Ltd., Torii Pharmaceutical Co. Ltd., and Novartis Pharma K.K. within the last 3 years. SM, TK, KI, and DB are employees of the study sponsor Novartis. The authors report no other conflicts of interest in this work.

\section{References}

1. Vital Statistics, Ministry of Health, Labor and Welfare Japan. 2014. Available from: http://www.mhlw.go.jp/english/new-info/. Accessed December 12, 2015.

2. Fukuchi Y, Fernandez L, Kuo HP, et al. Efficacy of tiotropium in COPD patients from Asia: a subgroup analysis from the UPLIFT trial. Respirology. 2011;16(5):825-835.

3. Ishikawa N, Hattori N, Kohno N, Kobayashi A, Hayamizu T, Johnson M. Airway inflammation in Japanese COPD patients compared with smoking and nonsmoking controls. Int J Chron Obstruct Pulmon Dis. 2015;10:185-192. 
4. Global Strategy for the Diagnosis, Management, and Prevention of Chronic Obstructive Pulmonary Disease. Global Initiative for Chronic Obstructive Lung Disease (GOLD 2016). Available from: http://www. goldcopd.com. Accessed January 6, 2016.

5. Japanese Respiratory Society. Guidelines for the Diagnosis and Treatment of COPD. 4th edition. Japanese Respiratory Society; 2013. Available from: https://www.jrs.or.jp/modules/guidelines/index. php?content_id=1. Accessed December 12, 2015.

6. Beeh KM, Korn S, Beier J, et al. Effect of QVA149 on lung volumes and exercise tolerance in COPD patients: the BRIGHT study. Respir Med. 2014;108(4):584-592.

7. Dahl R, Chapman KR, Rudolf M, et al. Safety and efficacy of dual bronchodilation with QVA149 in COPD patients: the ENLIGHTEN study. Respir Med. 2013;107(10):1558-1567.

8. Mahler DA, Decramer M, D’Urzo A, et al. Dual bronchodilation with QVA149 reduces patient-reported dyspnoea in COPD: the BLAZE study. Eur Respir J. 2014;43(6):1599-1609.

9. Wedzicha JA, Decramer M, Ficker JH, et al. Analysis of chronic obstructive pulmonary disease exacerbations with the dual bronchodilator QVA149 compared with glycopyrronium and tiotropium (SPARK): a randomised, double-blind, parallel-group study. Lancet Respir Med. 2013;1(3):199-209.

10. Bateman ED, Ferguson GT, Barnes N, et al. Dual bronchodilation with QVA149 versus single bronchodilator therapy: the SHINE study. Eur Respir J. 2013;42(6):1484-1494.
11. Asai K, Minakata Y, Hirata K, et al. QVA149 once-daily is safe and well tolerated and improves lung function and health status in Japanese patients with COPD: The ARISE study. European Respiratory Society Annual Congress 2013. Barcelona, Spain; 2013. p. P3392.

12. Horita N, Kaneko T. Role of combined indacaterol and glycopyrronium bromide (QVA149) for the treatment of COPD in Japan. Int J Chron Obstruct Pulmon Dis. 2015;10:813-822.

13. Calverley P, Pauwels RA, Jones PW, Anderson JA, Vestbos J. The severity of airways obstruction as a determinant of treatment response in COPD. Int J Chron Obstruct Pulmon Dis. 2006;1(3):209-218.

14. Vogelmeier CF, Bateman ED, Pallante J, et al. Efficacy and safety of once-daily QVA149 compared with twice-daily salmeterol-fluticasone in patients with chronic obstructive pulmonary disease (ILLUMINATE): a randomised, double-blind, parallel group study. Lancet Respir Med. 2013;1(1):51-60.

15. Zhong N, Wang C, Zhou X, et al; LANTERN Investigators. LANTERN: a randomized study of QVA149 versus salmeterol/fluticasone combination in patients with COPD. Int J Chron Obstruct Pulmon Dis. 2015;10:1015-1026.

16. Wedzicha JA, Dahl R, Buhl R, et al. Pooled safety analysis of the fixeddose combination of indacaterol and glycopyrronium (QVA149), its monocomponents, and tiotropium versus placebo in COPD patients. Respir Med. 2014;108(10):1498-1507. 


\section{Supplementary material}

Table SI List of relevant national and local ethics review boards

I. United States: Food and Drug Administration

2. Argentina: Administracion Nacional de Medicamentos, Alimentos y TecnologiaMedica

3. Argentina: Human Research Bioethics Committee

4. Argentina: Ministry of Health

5. Australia: Department of Health and Ageing Therapeutic Goods Administration

6. Australia: Human Research Ethics Committee

7. Australia: National Health and Medical Research Council

8. Bulgaria: Bulgarian Drug Agency

9. Bulgaria: Ministry of Health

10. Canada: Health Canada

II. China: Food and Drug Administration

12. Finland: Ethics Committee

13. Finland: Ministry of Social Affairs and Health

14. Finland: Finnish Medicines Agency

15. France: Afssaps - Agencefrançaise de sécurité sanitaire des produits de santé (Saint-Denis)

16. France: Direction Générale de la Santé

17. France: French Data Protection Authority

18. France: Haute Autorité de Santé Transparency Commission

19. France: Institutional Ethical Committee

20. France: Ministry of Health

21. France: National Consultative Ethics Committee for Health and Life Sciences

22. Germany: Ethics Commission

23. Germany: Federal Institute for Drugs and Medical Devices

24. Germany: Federal Ministry of Education and Research

25. Germany: Federal Ministry of Food, Agriculture and Consumer Protection

26. Germany: German Institute of Medical Documentation and Information

27. Germany: Ministry of Health

28. Germany: Paul-Ehrlich-Institut

29. Guatemala: MSPAS - Ministerio de SaludPública y Asistencia Social: Programa Nacional de Farmacovigilancia

30. Hungary: Research Ethics Medical Committee

31. Hungary: National Institute of Pharmacy

32. India: Central Drugs Standard Control Organization

33. India: Department of Atomic Energy

34. India: Drugs Controller General of India

35. India: Indian Council of Medical Research

36. India: Institutional Review Board

37. India: Ministry of Health

38. India: Ministry of Science and Technology

39. India: Science and Engineering Research Council

40. Japan: Ministry of Health, Labor and Welfare

41. Mexico: Ethics Committee

42. Mexico: Federal Commission for Protection Against Health Risks

43. Mexico: Federal Commission for Sanitary Risks Protection

44. Mexico: Ministry of Health

45. Mexico: National Council of Science and Technology

46. Mexico: National Institute of Public Health, Health Secretariat

47. The Netherlands: Independent Ethics Committee

48. The Netherlands: Dutch Health Care Inspectorate

49. The Netherlands: Medical Ethics Review Committee (METC)

50. The Netherlands: Medicines Evaluation Board (MEB)

5I. The Netherlands: The Central Committee on Research Involving Human Subjects (CCMO)

52. Panama: Ministry of Health

53. Philippines: Department of Health

54. Philippines: Bureau of Food and Drugs

55. Poland: Office for Registration of Medicinal Products, Medical Devices and Biocidal Products

56. Poland: Ministry of Health

57. Poland: Ministry of Science and Higher Education 
International Journal of COPD

\section{Publish your work in this journal}

The International Journal of COPD is an international, peer-reviewed journal of therapeutics and pharmacology focusing on concise rapid reporting of clinical studies and reviews in COPD. Special focus is given to the pathophysiological processes underlying the disease, intervention programs, patient focused education, and self management protocols.

This journal is indexed on PubMed Central, MedLine and CAS. The manuscript management system is completely online and includes a very quick and fair peer-review system, which is all easy to use. Visit http://www.dovepress.com/testimonials.php to read real quotes from published authors 